\title{
EFFECTS OF COMBINED EXPOSURE TO DICHLORVOS AND MONOCROTOPHOS ON HEPATOTOXICITY IN RATS
}

\author{
Vinesh Kumar $^{1,2 *}$, Pawan Kumar Basniwal ${ }^{2}$ and R. Vijayaraghavan ${ }^{1}$ \\ ${ }^{1}$ Division of Pharmacology and Toxicology, Defense Research and Development Establishment (DRDE), \\ Gwalior- 474002, Madhya Pradesh, India \\ ${ }^{2}$ Department of Pharmaceutical Chemistry, Lal Bahadur Shastri College of Pharmacy, Jaipur-302004, \\ Rajasthan, India \\ *E-mail: vineshkc@gmail.com \\ Tel.: +919828262634.
}

Received: Mar 07, 2018 / Revised: Apr 11, 2018 / Accepted: Apr 12, 2018

\begin{abstract}
Blind use of organophosphates as pesticides for enhancing productivity in agriculture leads to hormonal imbalance, infertility, thyroid dysfunctioning and the degree of effects produced depends on the extent of exposure to pesticides. Thus, the present study was planned to determine the effect of individual and combined exposure to dichlorvos (DDVP) and monocrotophos (MCP) on some selected biochemical variables suggestive of hepatic damage in rats. The monocrotophos clearly possessed the propensity to exacerbate hepatotoxicity when administered even at a relatively low dose, while the exact mechanisms by which monocrotophos potentiate the toxicity needs further investigation. The possibility of oxidative stress in the augmentation of hepatotoxicity was investigated that MCP is more potent in inducing oxidative stress. Therefore, the present study provides some interesting new observations for possible co-exposure to organophosphates. The coexposure to DDVP and MCP may produce synergistic effects at some extent.
\end{abstract}

Key words: Dichlorvos, Monocrotophos, Hepatotoxicity, Rats, Pesticide, Organophosphate.

\section{INTRODUCTION}

Pesticides have been used in agriculture for centuries to increase food production by removing unwanted insects and controlling disease vectors (Environmental Protection Agency US, 2000). Around four million tons of pesticides are applied to crops annually for pest control over the world, but less than one percent of the total applied pesticides reach the target pests (Pimentel, 1983). This massive use causes run off of pesticides from agricultural fields leading to contamination and bioaccumulation in tissues of many species resulting in development of toxicity (Elia et al 2006).

These pesticides are unselective and toxic to wide variety of species including humans (Dawson et al 2010). Poisoning occurs as a result of agricultural use, accidental exposure, suicide and, rarely homicidal use (Aygun, 2004).

Consumption of contaminated food items with pesticides above maximum residue level results in development of short term and long term adverse effects. It is evident from the incident in which many people died after consumption of pesticide contaminated flour (Gupta, 2004).

Action of pesticides on different body organs affects normal body functioning and causes problems like hepatitis, degeneration of liver, dyspnea and burning sensation in urine (Azmi et al 2006; Hettwer, 1975). Exposure to pesticides can affect hormonal balance, reproduction, thyroid functioning (Tyler et al 1998; Ewing, 1999). Degree of effects produced depends on the extent of exposure to pesticides (Chitra et al 2006). Organophosphorus (OP) toxicity is one of the major health issues globally and it results 
around 200,000 deaths per year all over the world due to self ingestion of these compounds (Eddleston, 2008). Oxidative damage is thought to be an important mechanism of damage in organophosphate pesticides toxicity (Banerjee et al 2001; Delescluse et al 2001; Halliwell et al 2004; Dwivedi et al 2011). Organophosphate pesticides have also been reported to reduce antioxidant enzyme activity, enhance the production of lipid peroxides and reduce the level of cellular antioxidants (Julka et al 1992). Pesticides, especially organophosphate pesticides, induce oxidative stress both in vivo and in vitro (Bagchi et al 1995; Yang et al 1998). Dichlorvos, also known as DDVP or DDVF (2, 2dichlorovinyl dimethyl phosphate) is a highly volatile, directly acting acetylcholine esterase inhibitor (Environmental Protection Agency US, 2000). The irreversible binding to and subsequent inactivation of acetylcholine esterase, the enzyme that normally catalyzes the hydrolysis of acetylcholine (ACh) at neuromuscular junctions and other cholinergic synapses, is generally believe to be the major mechanism of their toxicity. The subsequent accumulation of $\mathrm{ACh}$ in the cholinergic clefts causes overstimulation of the peripheral as well as the central cholinergic nervous system resulting in clinical manifestation in the form of acute cholinergic crisis (Taylor, 1996).

Another widely used pesticide, Monocrotophos (dimethyl (E)-1-methyl-2-(methylcarbamoyl) vinyl phosphate) is a broad spectrum systemic insecticide and acaricide used on variety of crops such as cotton, rice, and sugarcane. Exposure of monocrotophos is known to produce a variety of biochemical changes in mammals, aquatic and other experimental animals (Nemcsok et al 1987; Sultatos et al 1994; Waite et al 1992). It is a systemic pesticide harmful to human beings, affecting eyes and the CNS (Horrigan et al 2002). Monocrotophos along with endosulfan interferes with NADPH dependent monoxygenase mechanism and is effective inducers of NADPH cytochrome $\mathrm{C}$ reductase (Ramaneswari et al 2008).

Both DDVP and MCP possess different characteristics and these compounds produce varying degree of toxic effects. Liver is known to be the major target organ for pesticides, and it is an important organ for metabolic waste excretion and pesticide elimination (Shugart et al 1992). Analysis of biochemical parameters could help to identify target organs of toxicity. It may also provide an early warning signal in stressed organism (Folmar, 1993). OPs have been reported to cause enzyme induction particularly of ALP, ALT, AST, GGT, and LDH (Kalender et al 2005). Changes in the levels of these enzymes may differ depending on the exposure time and dose of OP. It has been previously suggested that organophosphates may phosphorylate and inhibit the hydroxymethylglutaryl CoA reductase, the key enzyme in cholesterol production (Ryhanen et al 1984). Increase in the activities of the liver specific enzymes, transaminases, alanine aminotransferase (ALT) and aspartate aminotransferase (AST) in blood have been attributed to tissue damage, particularly the liver and are considered as diagnostic and sensitive markers of hepatic damage (Reichling et al 1988). Hence, measurement of transaminase activities in plasma has been used as an indicator of hepatotoxicity of pesticides (Agrahari et al 2007). AST is an enzyme that is normally present in liver and heart cells. The blood AST levels are thus elevated with liver damage or with an insult to the heart. While, as a liver specific enzyme, ALT is significantly elevated in conditions of hepatic damage although increases can occur in connection with damage of heart as well. Hence, AST/ALT ratio is often employed for the differential diagnosis of liver damage, with the higher ratio indicating more severe damage.

Various studies have been carried out on individual effects of these two organophosphates but there are only few studies on combined exposure of DDVP and MCP (Dwivedi et al 2010; Dwivedi et al 2011). Considering the fact that different pesticides are simultaneously being used, there is every possibility of population getting exposed to multiple pesticides. Thus, the present study was planned to determine the effect of individual and combined exposure to DDVP and MCP on some selected biochemical variables suggestive of hepatic damage in rats.

\section{EXPERIMENTAL Chemicals}

The two organophosphorous compounds, Dichorvos (Nuvan, 76\%) and MCP (Kadett, 36\%) were obtained from Syngenta chemicals and P.I. Industries Ltd, respectively. All other chemicals and reagents were of analytical grade. All other analytical laboratory chemicals and reagents were purchased from Merck (Germany), Sigma (USA) or BDH chemicals (Mumbai, India). Ultra pure water prepared by Millipore (New Delhi, India) was used throughout the experiment to 
avoid metal contamination and for the preparation of reagents and buffers used for various biochemical assays in our study.

\section{Animals}

Wistar rats (110-120 g) were obtained from Defence Research and Development Establishment (DRDE) animal facility and prior to use, were acclimatized for 7 days $12 \mathrm{~h}$ light/dark cycle. The animal ethical committee of DRDE, Gwalior approved the protocols for the experiments. The animals were housed in stainless steel cages in an air-conditioned room with temperature maintained at $25 \pm 2^{\circ} \mathrm{C}$. Rats were allowed standard pellet diet (Ashirwad Feeds, Chandigarh, India) throughout the experiment and water ad libitum. Different doses (high dose and low dose) of DDVP and MCP were selected to study the effects on blood biochemical variables in experimental animals (Table 1).

\section{Biochemical assays}

Blood and tissue lipid peroxidation was measured (Ohkawa et al 1979) and modified (Saxena et al 2004). Reactive oxygen species (ROS) assay was performed (Socci et al 1999). The activity of SGOT and SGPT were assayed according to the literature method (Reitman et al 1957). Reduced glutathione (GSH) and oxidized glutathione (GSSG) levels were measured fluorometrically (Hissin et al 1974). Catalase activity in tissue was assayed following the procedure reported in literature (Sinha, 1972). SOD activity was assayed and total tissue protein was measured by the reported methods (Nishikimi et al 1972; Kakkar et al 1984; Lowry et al 1951).

Table 1. Dosing of the groups of animals

\begin{tabular}{|c|c|c|c|}
\hline \multirow{2}{*}{ Group } & \multirow{2}{*}{$\begin{array}{c}\text { Number of } \\
\text { animals }\end{array}$} & \multicolumn{2}{|c|}{ Drug, dose and route } \\
\cline { 3 - 4 } & Six & Drinking water (blank) & Drinking water (blank) \\
\hline Group 1 & Six & $\begin{array}{c}\text { Dichlorvos, } 2.5 \mathrm{mg} / \mathrm{kg}, \\
\text { subcutaneously }\end{array}$ & $\begin{array}{c}\text { Dichlorvos, } 2.0 \mathrm{mg} / \mathrm{kg}, \\
\text { orally }\end{array}$ \\
\hline Group 2 & Six & $\begin{array}{c}\text { Monocrotophos, } 2.0 \\
\mathrm{mg} / \mathrm{kg}, \text { orally }\end{array}$ & $\begin{array}{c}\text { Monocrotophos, } 1.8 \\
\mathrm{mg} / \mathrm{kg} \text {, orally }\end{array}$ \\
\hline Group 3 & Six & $\begin{array}{c}\text { Dichlorvos, } 2.5 \mathrm{mg} / \mathrm{kg}, \\
\text { subcutaneously } \\
+ \text { Monocrotophos, } \\
\text { Group 4 }\end{array}$ & $\begin{array}{c}\text { Dichlorvos, } 1 \mathrm{mg} / \mathrm{kg} \text { orally } \\
+ \text { Monocrotophos, } 1 \mathrm{mg} / \mathrm{kg} \\
\text { orally }\end{array}$ \\
\hline
\end{tabular}

\section{Statistical analysis}

The results are expressed as the mean \pm SEM of number of observations. Comparisons of means were carried out using one way ANOVA followed by student ' $t$ ' test to compare means between the different treatment groups. Differences were considered significant at $\mathrm{P}<0.05$ unless otherwise stated in the text.

\section{RESULTS}

\section{Effects at high dose}

Effects on biochemical variables indicative of liver damage

Effects of individual and combined exposure to DDVP and MCP on biochemical variables indicative of hepatic damage are presented in the Table 2. Exposure to MCP alone led to a significant increase in serum AST and ALP activities suggesting hepatic injury while ALT activity decreased significantly. Exposure to DDVP produced no change in these variables.
Combined exposure to DDVP and MCP had no additional synergistic additive effects however; the increased AST activity during combined exposure was predominantly due to MCP.

\section{Effects at low dose}

Hepatic ROS and TBARS levels

Effect of DDVP and MCP on some hepatic biochemical variables is shown in Figure 1. Coexposure to DDVP and MCP produced a nonsignificant elevation in ROS level. Interestingly, exposure to DDVP and MCP led to a significant elevation in TBARS level both in alone and combination groups (Figure 3).

\section{Hepatic GSH and GSSG levels}

Effect of DDVP and MCP on hepatic GSH and GSSG levels is shown in Figure 2. GSH and GSSG levels did not found to alter following exposure to MCP and DDVP whether administered alone or in combination. 
Table 2. Effects of individual and combined exposure of DDVP and MCP on hepatic ALT and AST levels in rats at high dose

\begin{tabular}{|c|c|c|c|c|}
\hline Variables & Normal & DDVP & MCP & DDVP + MCP \\
\hline S-AST (U/L) & $35.85 \pm 1.76^{*}$ & $33.60 \pm 1.06^{*}$ & $138.45 \pm 9.93^{\dagger}$ & $134.58 \pm 9.0{ }^{\dagger}$ \\
\hline S-AST (U/L) & $73.59 \pm 4.28^{*}$ & $73.41 \pm 4.40^{*}$ & $67.93 \pm 3.60^{*}$ & $78.24 \pm 7.30^{*}$ \\
\hline $\begin{array}{c}\text { ALP } \\
\text { (mg of P/hr/mg protein) }\end{array}$ & $0.13 \pm 0.05^{*}$ & $0.16 \pm 0.02^{*}$ & $0.18 \pm 0.04^{*}$ & $0.19 \pm 0.03^{*}$ \\
\hline
\end{tabular}

S-AST- Serum aspartate amino transferase; S-ALT- Serum alanine amino transferase; ALP- Alkaline phosphatase, values are mean \pm SE; $n=5$; Data was analyzed using analysis of variance (ANOVA) followed by Dunnett's test. ${ }^{*}+$ Differences between values with matching symbol notations within each row are not statistically significant at a $5 \%$ level of probability

\section{Hepatic SOD and catalase activities}

The activity of SOD decreased significantly in MCP exposed group as well as in the combination group. However, the activity of catalase was found to be decreased in DDVP and combination group (Figure 3).

\section{SGOT and SGPT activity}

The activities of SGOT and SGPT indicative of liver damage in rats are depicted in Figure 4. Serum SGOT and SGPT activities increased on exposure to DDVP and MCP individually and on co-exposure suggesting liver injury.
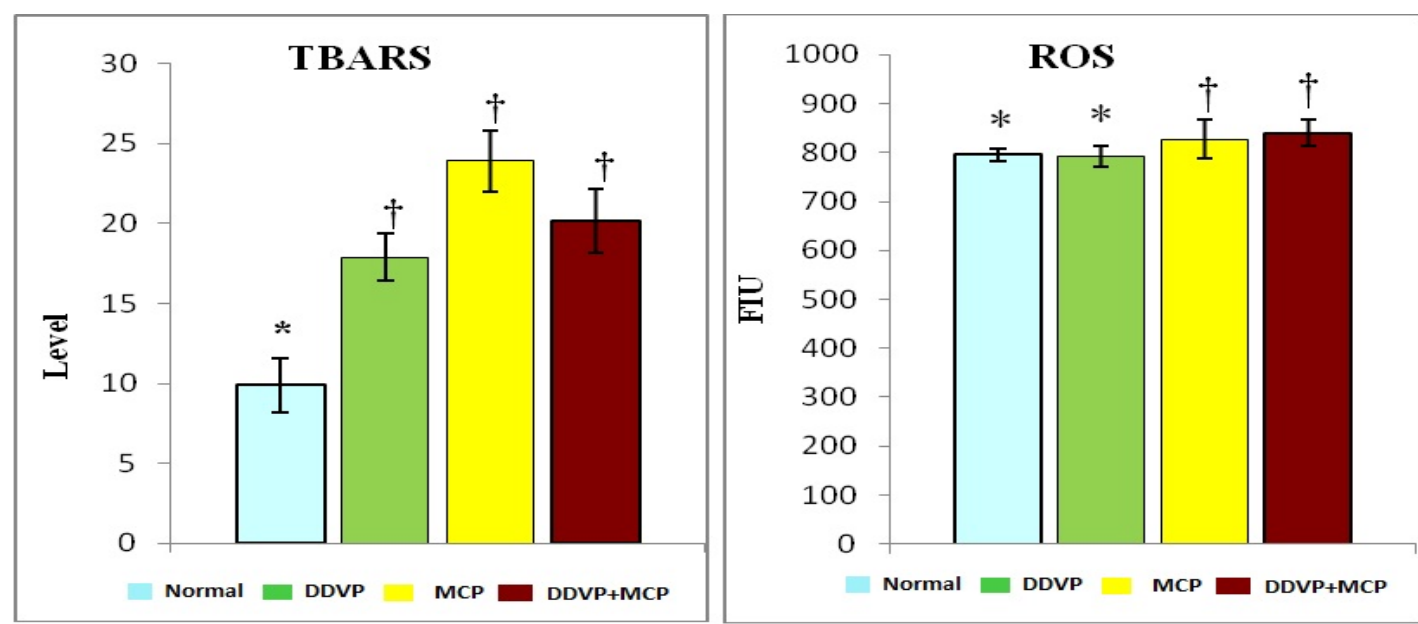

ROS, reactive oxygen species as FIU; TBARS, thiobarbituric acid reactive species as $\mathrm{mg} / \mathrm{gm}$ tissue; values are $\mathrm{mean} \pm \mathrm{SE} ; \mathrm{n}=5$

*,+Differences between values with matching symbol notations within each column are not statistically significant at a $5 \%$ level of probability

Fig. 1. Effect of individual and combined exposure to DDVP and MCP on ROS and TBARS in rat liver at low dose
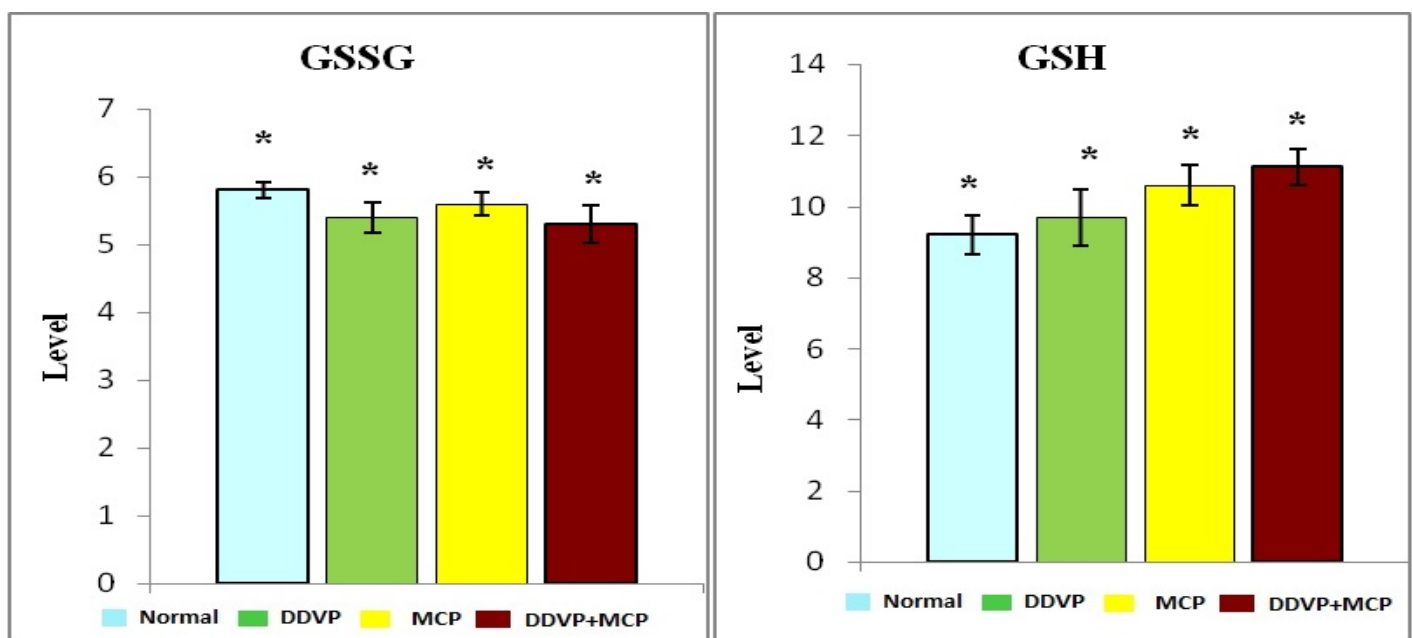

$\mathrm{GSH}$, reduced glutathione as $\mathrm{mg} / \mathrm{gm}$ tissue; GSSG, oxidized glutathione as $\mathrm{mg} / \mathrm{gm}$ tissue; values are mean $\pm \mathrm{SE} ; \mathrm{n}=5$ *Differences between values with matching symbol notations within each column are not statistically significant at a $5 \%$ level of probability

Fig. 2. Effect of individual and combined exposure to DDVP and MCP on GSH and GSSG in rat liver low dose 


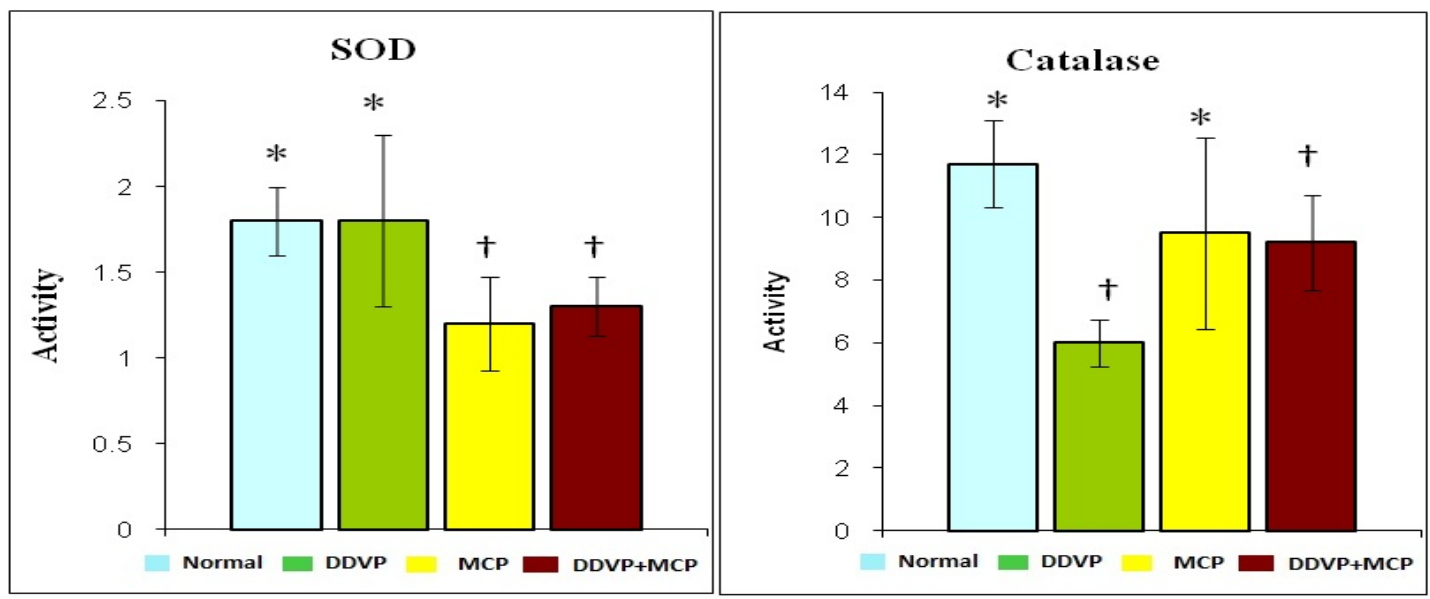

$\mathrm{SOD}=$ superoxide dismutase as units $/ \mathrm{min} / \mathrm{mg}$ protein; catalse as $\mu$ moles $/ \mathrm{min} / \mathrm{mg}$ protein; values are means $\pm \mathrm{SE} ; \mathrm{n}=5$

*,+Differences between values with matching symbol notations within each row are not statistically significant at a $5 \%$ level of probability

Fig. 3. Effect of individual and combined exposure to DDVP and MCP on SOD and Catalase in rat liver at low dose

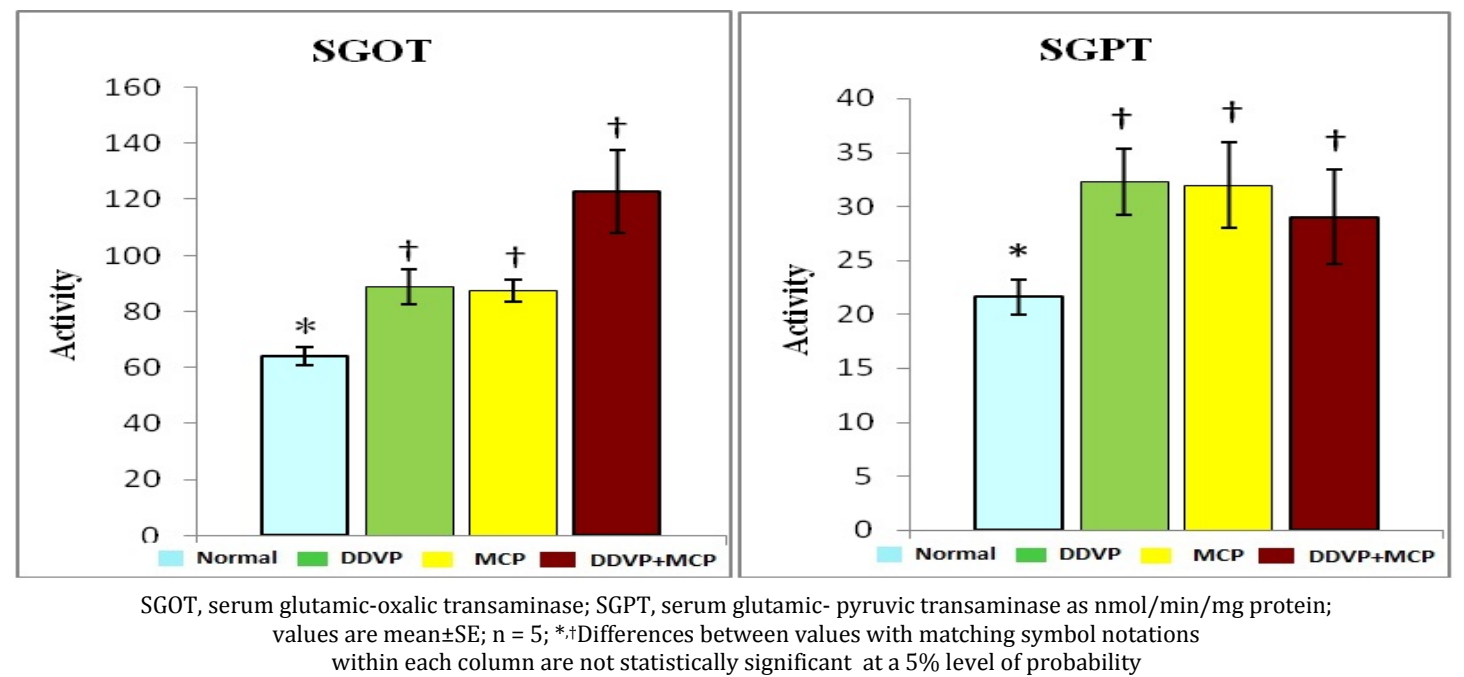

Fig. 4. Effect of individual and combined exposure to DDVP and MCP on SGOT and SGPT in rats at low dose

\section{DISCUSSION}

Organophosphorus pesticides being lipophilic interact with cells through lipid-rich biomembranes and damage membrane as a result of oxidative polyunsaturated fatty acids of the bilayer known as lipid per oxidation (Mittal et al 2006; Naqvi et al 1992; Yamano et al 1992). Transaminases (SGOT and SGPT) are critical enzymes in the biological processes. Increased activity of transaminases is mainly due to the leakage of these enzymes from liver cytosol into the blood stream. Thus, their increased activity in serum is an indicative of liver damage. Higher dose of both the toxicants produced liver injury and the impairment in liver function was supported by the liver function test observations. Exposure to DDVP or MCP led to hepatic damage indicated by increased SGOT and
SGPT activities in serum. There was however more pronounced increase in SGOT activity in animals co-exposed to DDVP and MCP suggesting their cumulative effect (Dwivedi et al 2010). Since, higher dose of DDVP and MCP were capable enough of producing pronounced toxicity, a lower dose toxicity study was carried out to investigate changes in oxidative stress which may be a potential cause of toxicity.

Earlier reports have investigated toxic effects of individual exposure of DDVP and MCP in experimental animals. However, there are only few studies in the literature which reported combined toxicity of these toxicants (Dwivedi et al 2011). There is paucity of evidence as the interactions between these two OP's have not been investigated in detail. The present study thus, observed the effects of combined exposure 
of DDVP and MCP on changes in the parameters indicative of oxidative stress in rats. The results showed increased production of reactive oxygen species, lipid peroxidation and altered serum transaminases, which might be contributing to organophosphates toxicity and tissue damage.

It is apparent that, although inhibition of cholinesterases plays a key role in the toxicology of organophosphates the inhibition of other enzyme systems and the direct effects of organophosphates on tissues are also important. Organophosphates are known to induce oxidative stress, but there is little evidence of changes in antioxidant system after intoxication with organophosphate compound (Hai et al 1997). Reports indicate that toxic manifestations induced by organophosphates may be associated with the enhanced production of ROS. It is also reported that different classes of pesticides induce reactive oxygen species (ROS) leading to tissue oxidative damage (Bagchi et al 1995). Also excessive amounts of ROS generation due to high-energy consumption coupled with inhibition of oxidative phosphorylation leads to decreased capacity of cells to maintain its energy levels (Milatovic et al 2006). We observed increased free radical generation in the present study predominantly in the animals given MCP alone and in combination with DDVP (Dwivedi et al 2011).

Reports indicate that enzyme activities associated with antioxidant defence mechanisms are altered by insecticides both in vivo and in vitro (Gultekin et al 2000; Oncu et al 2002). Both the increased production of reactive oxygen species and attenuation of the antioxidant barrier of the organism are likely to induce oxidative stress, leading to tissue damage,

\section{REFERENCES}

Abdollahi M, Ranjbar A, Shadnia S, Nikfar S, Rezaie A. Pesticides and oxidative stress: a review. Med. Sci. Monit. 2004;10(6):RA141-7.

Agrahari S, Pandey KC, Gopal K. Biochemical alteration induced by monocrotophos in the blood plasma of fish, Channa punctatus (Bloch). Pest. Biochem. Physiol. 2007; 88(3):268-72. [DOI: 10.1016/j.pestbp.2007.01.001]

Akhgari M, Abdollahi M, Kebryaeezadeh A, Hosseini R, Sabzevari 0. Biochemical evidence for free radicalinduced lipid peroxidation as a mechanism for subchronic toxicity of malathion in blood and liver of rats. Human. Exp. Toxicol. 2003; 22(4):205-11. [DOI: 10.1191/096032 7103ht346oa]

Aygun D. Diagnosis in an acute organophosphate poisoning: report of three interesting cases and review of the literature. Eur. J. Emerg. Med. 2004;11(1):55-8.

Azmi MA, Naqvi SN, Azmi MA, Aslam M. Effect of pesticide residues on health and different enzyme levels in the blood of farm workers from Gadap (rural area) Karachi- tubular necrosis and cardiotoxicity in acute as well as in sub-chronic OP intoxication (Abdollahi et al 2004; Akhgari et al 2003). In the present observation also, SOD activity which is a superoxide scavenger, inhibited in MCP alone and combination groups suggesting excessive generation of reactive oxygen species followed by a parallel depletion of antioxidant enzymes. On the contrary, no changes in GSH level have been reported either in individual or in combination group suggestive of protective effect of body against the toxic effect of these toxicants.

\section{CONCLUSION}

Our findings demonstrated that monocrotophos clearly possessed the propensity to exacerbate hepatotoxicity when administered even at a relatively low dose. While the exact mechanism/s by which OPs such as monocrotophos potentiate the toxicity needs further investigation, we currently examined the possibility of oxidative stress in the augmentation of hepatotoxicity. On comparison between DDVP and MCP administered individually, MCP seems to be more potent in inducing oxidative stress. Thus, the present study provides some interesting new observations for possible co-exposure to organophosphates. On the basis of present observation it however may be suggested that co-exposure to DDVP and MCP may produce synergistic effects at some extent. The mechanism underlying their combined toxicity needs further exploration. It would also be of interest to determine the impact of OPs at further low concentrations (at levels not causing AChE inhibition) on liver degeneration.

Pakistan. Chemosphere 2006;64(10):1739-44. [DOI: 10.10 16/j.chemosphere.2006.01.016]

Bagchi D, Bagchi M, Hassoun EA, Stohs SJ. In vitro and in vivo generation of reactive oxygen species, DNA damage and lactate dehydrogenase leakage by selected pesticides. Toxicology 1995;104(1-3):129-40. [DOI: 10.1016/0300483X(95)03156-A]

Banerjee BD, Seth V, Ahmed RS. Pesticide-induced oxidative stress: perspectives and trends. Rev. Environ. Health 2001; 16(1):1-40.

Chitra GA, Muraleedharan VR, Swaminathan T, Veeraraghavan D. Use of pesticides and its impact on health of farmers in South India. Int. J. Occup. Environ. Health 2006;12(3):228-33. [DOI: 10.1179/oeh.2006.12.3.228]

Dawson AH, Eddleston M, Senarathna L, Mohamed F, Gawarammana I, Bowe SJ, Manuweera G, Buckley NA. Acute human lethal toxicity of agricultural pesticides: a prospective cohort study. PLoS Med. 2010;7(10): e1000357 [DOI: 10.1371/journal.pmed.1000357] 
Delescluse C, Ledirac N, Li R, Piechocki MP, Hines RN, Gidrol $\mathrm{X}$, Rahmani R. Induction of cytochrome P450 1A1 gene expression, oxidative stress, and genotoxicity by carbaryl and thiabendazole in transfected human HepG2 and lymphoblastoid cells. Biochem. Pharmacol. 2001;61(4):399-407. [DOI: 10.1016/S0006-2952(00)005 62-1]

Dwivedi N, Bhutia YD , Kumar V, Yadav P, Kushwaha P, Swarnkar H, Flora SJ. Effects of combined exposure to dichlorvos and monocrotophos on blood and brain biochemical variables in rats. Human Exp. Toxicol. 2010;29(2):121-9. [DOI: 10.1177/0960327109357212]

Dwivedi N, Flora SJ. Concomitant exposure to arsenic and organophosphates on tissue oxidative stress in rats. Food Chem. Toxicol. 2011;49(5):1152-9. [DOI: 10.1016/j.fct.20 11.02.007]

Eddleston M. The pathophysiology of organophosphorus pesticide self-poisoning is not so simple. Neth. J. Med. 2008;66(4):146-8.

Elia AC, Galarini R, Dorr AJM, Taticchi MI. Bioaccumulation of heavy metals, organochlorine pesticides, and detoxication biochemical indexes in tissues of Ictalurus melas of Lake Trasimeno. Bull. Environ. Contam. Toxicol. 2006;76(1):132-9. [DOI: 10.1007/s00128-005-0899-1]

Environmental Protection Agency US. Health and environmental effects profile for dichlorvos. 2000; 11-5.

Ewing RD. Diminishing returns: Salmon decline and pesticides. Funded by the Oregon Pesticide Education Network, Biotech Research and Consulting, Inc., Corvallis. 1999; 55.

Flessel P, Quintana PJE, Hooper K. Genetic toxicity of malathion: a review. Environ. Mol. Mutagen. 1993;22(1):717. [DOI: $10.1002 / \mathrm{em} .2850220104]$

Folmar LC. Effects of chemical contaminants on blood chemistry of teleost fish: a bibliography and synopsis of selected effects. Environ. Toxicol. Chem. 1993;12(2):33775. [DOI: 10.1002/etc.5620120216]

Gultekin F, Ozturk M, Akdogan M. The effect of organophosphate insecticide chlorpyrifos-ethyl on lipid peroxidation and antioxidant enzymes (in vitro). Arch. Toxicol. 2000;74(9):533-8. [DOI: 10.1007/s0020400001 67]

Gupta PK. Pesticide exposure-Indian scene. Toxicology 2004;198(1-3):83-90. [DOI: 10.1016/j.tox.2004.01.021]

Hai DQ, Varga SI, Matkovics B. Organophosphate effects on antioxidant system of carp (Cyprinus carpio) and catfish (Ictalurus nebulosus). Comp. Biochem. Physiol. C Pharmacol. Toxicol. Endocrinol. 1997;117(1):83-8. [DOI: 10.1016/S0742-8413(96)00234-4]

Halliwell B, Whiteman M. Measuring reactive species and oxidative damage in vivo and in cell culture: how should you do it and what do the results mean? Br. J. Pharmacol. 2004;142(2):231-55. [DOI: 10.1038/sj.bjp.0705776]

Hettwer H. Histochemical investigations on liver and kidney of the rat after intoxication with organophosphates. Acta Histochem. 1975;52(2):239-52.

Hissin PJ, Hilf R. A fluorometric method for determination of oxidized and reduced glutathione in tissues. Anal. Biochem. 1976;74(1):214-26. [DOI: 10.1016/0003-2697 (76)90326-2]

Horrigan L, Lawrence RS, Walker P. How sustainable agriculture can address environmental and human health harms of industrial agriculture. Environ. Health Perspect. 2002;110(5):445-56.

Julka D, Pal R, Gill KD. Neurotoxicity of dichlorvos: effect on antioxidant defense system in the rat central nervous system. Exp. Mol. Pathol. 1992;56(2):144-52. [DOI: 10.10 16/0014-4800(92)90031-6]

Kakkar P, Das B, Viswanathan PN. A modified spectrophotometric assay of superoxide dismutase. Indian J. Biochem. Biophy. 1984;21(2):130-2.

Kalender S, Ogutcu A, Uzunhisarcikli M, Acikgoz F, Durak D, Ulusoy Y, Kalender Y. Diazinon-induced hepatotoxicity and protective effect of vitamin $\mathrm{E}$ on some biochemical indices and ultrastructural changes. Toxicology 2005: 211(3):197-206. [DOI: 10.1016/j.tox.2005.03.007]

Lowry OH, Rosebrough NJ, Farr AL, Randall RJ. Protein measurement with the Folin phenol reagent. J. Biol. Chem. 1951;193(1):265-75.

Milatovic D, Gupta RC, Aschner M. Anticholinesterase toxicity and oxidative stress. ScientificWorldJournal 2006;6:295-310. [DOI: 10.1100/tsw.2006.38]

Mittal M, Flora SJ. Effects of individual and combined exposure to sodium arsenite and sodium fluoride on tissue oxidative stress, arsenic and fluoride levels in male mice. Chem. Biol. Interact. 2006;162(2):128-39. [DOI: 10.1016/j.cbi.2006.05.018]

Naqvi SM, Hasan M. Acetylhomocysteine thiolactone protection against phosphamidon-induced alteration of regional superoxide dismutase activity in central nervous system and its correlation with altered lipid peroxidation. Indian J. Exp. Biol. 1992;30(9):850-2.

Nemcsok J, Orban L, Asztalos B, Vig E. Accumulation of pesticides in the organs of carp, Cyprinus carpio L., at 4 degrees and 20 degrees C. Bull. Environ. Contam. Toxicol. 1987;39(3):370-8.

Nishikimi M, Appaji N, Yagi K. The occurrence of superoxide anion in the reaction of reduced phenazine methosulfate and molecular oxygen. Biochem. Biophys. Res. Commun. 1972;46(2):849-54. [DOI: 10.1016/S0006-291X(72)8021 8-3]

Ohkawa H, Ohishi N, Yagi K. Assay for lipid peroxides in animal tissues by thiobarbituric acid reaction. Anal. Biochem. 1979;95(2):351-8. [DOI: 10.1016/0003-2697 (79)90738-3]

Oncu M, Gultekin F, Karaoz E, Altuntas I, Delibas N. Nephrotoxicity in rats induced by chlorpryfos-ethyl and ameliorating effects of antioxidants. Human Exp. Toxicol. 2002;21(4):223-30. [DOI: 10.1191/0960327102ht225oa]

Pimentel D. Effect of pesticides on the environment. In: 10th International Congress on Plant Protection. Crydon: UK, 1983; pp. 685-91.

Ramaneswari K, Rao LM. Influence of endosulfan and monocrotophos exposure on the activity of NADPH cytochrome c reductase (NCCR) of Labeo rohita (Ham). J. Environ. Biol. 2008; 29(2):183-5.

Reichling JJ, Kaplan MM. Clinical use of serum enzymes in liver disease. Dig. Dis. Sci. 1988;33(12):1601-14.

Reitman S, Frankel S. A colorimetric method for the determination of serum glutamic oxaloacetic and glutamic pyruvic transaminases. Am. J. Clin. Pathol. 1957;28(1): 56-63.

Ryhanen R, Herranen J, Korhonen K, Penttila I, Polvilampi M, Puhakainen E. Relationship between serum lipids, lipoproteins and pseudocholinesterase during organophosphate poisoning in rabbits. Int. J. Biochem. 1984; 16(6):687-90. [DOI: 10.1016/0020-711X(84)90039-9]

Saxena G, Flora SJ. Lead-induced oxidative stress and hematological alterations and their response to combined administration of calcium disodium EDTA with a thiol chelator in rats. J. Biochem. Mol. Toxicol. 2004;18(4): 221-33. [DOI: 10.1002/jbt.20027] 
Shugart LR, McCarthy JF, Halbrook RS. Biological markers of environmental and ecological contamination: a review. Risk. Anal. 1992;12(3):353-60. [DOI: 10.1111/j.1539-692 4.1992.tb00687.x]

Sinha AK. Colorimetric assay of catalase. Anal. Biochem. 1972;47(2):389-94. [DOI: 10.1016/0003-2697(72)9013 2-7]

Socci DJ, Bjugstad KB, Jones HC, Pattisapu JV, Arendash GW. Evidence that oxidative stress is associated with the pathophysiology of inherited hydrocephalus in the H-Tx rat model. Exp. Neurol. 1999;155(1):109-17. [DOI: 10.10 06/exnr.1998.6969]

Sultatos LG. Mammalian toxicology of organophosphorus pesticides. J. Toxicol. Environ. Health 1994;43(3):271-89. [DOI: 10.1080/15287399409531921]

Taylor P. Anticholinesterase Agents. In: The Pharmacological Basis of Therapeutics, 9th edition, Hardman JG,
Limbird LE (eds). McGraw Hill, New York: USA, 1996; pp. 161-76.

Tyler CR, Jobling S, Sumpter JP. Endocrine disruption in wildlife: a critical review of the evidence. Crit. Rev. Toxicol. 1998;28(4):319-61.

Waite DT, Sommerstad H, Grover R, Kerr L, Westcott ND. Pesticides in ground water, surface water and spring runoff in a small Saskatchewan watershed. Environ. Toxicol. Chem. 1992;11(6):741-8. [DOI: 10.1002/etc.5620 110603]

Yamano T, Morita S. Hepatotoxicity of trichlorfon and dichlorvos in isolated rat hepatocytes. Toxicology 1992;76(1):69-77. [DOI: 10.1016/0300-483X(92)9001 9-B]

Yang W, Sun AY. Paraquat-induced free radical reaction in mouse brain microsomes. Neurochem. Res. 1998;23(1): 47-53. [DOI: 10.1023/A:1022497319548] 